\title{
The genome and life-stage specific transcriptomes of Globodera pallida elucidate key aspects of plant parasitism by a cyst nematode
}

\author{
James A Cotton ${ }^{1 \dagger}$, Catherine J Lilley ${ }^{2 \dagger}$, Laura M Jones ${ }^{2}$, Taisei Kikuchi ${ }^{4,5}$, Adam J Reid ${ }^{1}$, Peter Thorpe ${ }^{2,3}$, \\ Isheng J Tsai ${ }^{1,5,6}$, Helen Beasley ${ }^{1}$, Vivian Blok ${ }^{3}$, Peter J A Cock ${ }^{3}$, Sebastian Eves-van den Akker ${ }^{2,3}$, Nancy Holroyd', \\ Martin Hunt ${ }^{1}$, Sophie Mantelin ${ }^{3}$, Hardeep Naghra ${ }^{1,7}$, Arnab Pain ${ }^{1,8}$, Juan E Palomares-Rius ${ }^{3,9}$, Magdalena Zarowiecki ${ }^{1}$, \\ Matthew Berriman ${ }^{1 *}$, John T Jones ${ }^{3^{*}}$ and Peter E Urwin ${ }^{2^{*}}$
}

\begin{abstract}
Background: Globodera pallida is a devastating pathogen of potato crops, making it one of the most economically important plant parasitic nematodes. It is also an important model for the biology of cyst nematodes. Cyst nematodes and root-knot nematodes are the two most important plant parasitic nematode groups and together represent a global threat to food security.

Results: We present the complete genome sequence of G. pallida, together with transcriptomic data from most of the nematode life cycle, particularly focusing on the life cycle stages involved in root invasion and establishment of the biotrophic feeding site. Despite the relatively close phylogenetic relationship with root-knot nematodes, we describe a very different gene family content between the two groups and in particular extensive differences in the repertoire of effectors, including an enormous expansion of the SPRY domain protein family in G. pallida, which includes the SPRYSEC family of effectors. This highlights the distinct biology of cyst nematodes compared to the root-knot nematodes that were, until now, the only sedentary plant parasitic nematodes for which genome information was available. We also present in-depth descriptions of the repertoires of other genes likely to be important in understanding the unique biology of cyst nematodes and of potential drug targets and other targets for their control.

Conclusions: The data and analyses we present will be central in exploiting post-genomic approaches in the development of much-needed novel strategies for the control of G. pallida and related pathogens.
\end{abstract}

\section{Background}

There are over 4,100 species of plant parasitic nematodes [1] which collectively are an important threat to global food security. Damage caused to crops worldwide by plant parasitic nematodes has been estimated at $\$ 80$ billion per year [2]. The largest economic losses to agriculture are imposed by root-knot nematodes and cyst nematodes that both belong to the order Tylenchida.

\footnotetext{
*Correspondence: mb4@sanger.ac.uk; john.jones@hutton.ac.uk; p.e.urwin@ leeds.ac.uk

${ }^{\dagger}$ Equal contributors

'Wellcome Trust Sanger Institute, Wellcome Trust Genome Campus,

Cambridge CB10 1SA, UK

${ }^{3}$ The James Hutton Institute, Invergowrie, Dundee DD2 5DA, UK

${ }^{2}$ Centre for Plant Sciences, University of Leeds, Leeds LS2 9JT, UK

Full list of author information is available at the end of the article
}

The most widespread and damaging species of root-knot nematodes have a wide host range and are prevalent in Mediterranean, subtropical and tropical regions while cyst nematode species have more restricted host ranges and the most damaging species are found predominantly in more temperate agricultural regions. Both root-knot and cyst nematodes are obligate, sedentary endoparasites that have unique, biotrophic interactions with their host plants. A central feature of the parasitism is the establishment and maintenance of a permanent feeding site that sustains the nematode throughout its growth in the plant [3]. However, biotrophic parasitism of plants by root-knot nematodes and cyst nematodes has evolved independently [4] and this is reflected in the different feeding structures of these nematodes.

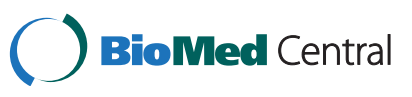

(c) 2014 Cotton et al.; licensee BioMed Central Ltd. This is an Open Access article distributed under the terms of the Creative Commons Attribution License (http://creativecommons.org/licenses/by/2.0), which permits unrestricted use, distribution, and reproduction in any medium, provided the original work is properly cited. 
The most economically important cyst nematode species are within the Heterodera and Globodera genera. Cyst nematodes cause significant damage to a range of crops worldwide, particularly potato, soybean, wheat and rice. Potato cyst nematode (PCN) is the collective term for the two species G. pallida and G. rostochiensis that are restricted to infecting a few species of Solanaceous plants. PCN is a major pest of the potato crop in cooltemperate areas of the world. Yield losses of potato in excess of $50 \%$ due to PCN are reported in the literature (for example, [5]). Although PCN is indigenous to South America, it was introduced into Europe in the 19th century with potato material used for resistance breeding against late blight [6] and is now widely distributed in Europe [7]. From here, PCN has spread to all major potato growing areas of the world including Ukraine and, more recently, Idaho in the USA [8,9]. Integrated pest management of G. pallida is based on partially resistant cultivars, crop rotation and nematicides. Resistance against the pathotypes of $G$. rostochiensis predominant in Europe is provided by the $\mathrm{H} 1$ gene, which is now available in many potato cultivars, for example, 'Maris Piper'. However, the lack of a comparable single, dominant natural resistance gene for G. pallida has resulted in an emphasis on multi-trait quantitative resistance that is difficult to breed and is more readily overcome by virulent pathotypes. Repeated use of cultivars resistant to $G$. rostochiensis has selected for G. pallida in mixed populations [10]. The slow decline rate of the dormant soil population of G. pallida makes crop rotation an extremely inefficient management practice $[11,12]$. Nematicides are thus currently essential to control G. pallida and allow favoured, susceptible potato cultivars to be grown at an economically viable cropping frequency. Recent legislation, however, has withdrawn or severely limited their use [13]. Consequently there is an urgent need to develop novel approaches for control of this and other cyst nematodes. Research in this direction will be significantly enhanced by a greater understanding of the molecular basis of the parasitic interaction and the key nematode genes required for this.

Cyst nematodes hatch as second stage juveniles (J2) from eggs contained within cysts in the soil. This process is usually initiated in response to chemicals released from roots of a potential host plant. Upon locating host roots they use their stylet to disrupt the plant tissue and migrate intracellularly through cortical cells towards the vascular cylinder where an initial feeding cell is selected. The nematode secretes proteins from pharyngeal gland cells through the bore of the stylet into the initial feeding cell thus inducing the formation of a syncytial feeding site. Localised cell wall dissolution and protoplast fusion cause the syncytium to progressively enlarge until it eventually incorporates up to 200 neighbouring cells [14]. The syncytium develops wall ingrowths to facilitate water and nutrient uptake from the xylem and acts as a strong nutrient sink, with phloem solutes transported at first apoplasmically and later via plasmodesmata. The syncytium is continually stimulated by stylet secretions and provides the growing cyst nematode with all the nutrients required for development into an adult male or an egg-laying female, a process that takes 3 to 6 weeks. Sex is determined by the size of the syncytium that is induced and whether it gains access to vascular tissues in order to supply plentiful nutrients (reviewed by [15]). The cuticle of the mature female, harbouring eggs containing quiescent J2s within her body, is tanned by a polyphenol oxidase to form the tough cyst that protects the eggs. The cyst becomes detached from the root following death of the plant and the eggs within can remain viable for many years.

Nematodes have been a focus of genomic projects since the 1990s when the free-living bacteriovore Caenorhabditis elegans became the first multicellular organism to have a completely sequenced genome [16]. This provided a valuable platform for genomics research in other nematode species, but it was a further decade before the first genome sequence became available for a parasitic nematode, the human filarial parasite Brugia malayi [17]. Genome sequences have subsequently been reported for a range of other nematode species [18-20], but only three plant parasitic nematodes: two root-knot nematode species [21] (Meloidogyne incognita [22] and M. hapla [23]) and most recently the pine wood nematode Bursaphelenchus xylophilus, a migratory endoparasite [24]. The draft genome sequence of G. pallida reported here is, to our knowledge, the first cyst nematode genome to be described and will serve as a valuable comparator for understanding the evolution of plant parasitism in nematodes. We describe the genome in detail, examining the gene content of G. pallida in the context of other published plant parasitic nematode genomes. Significantly, we use RNA-seq to examine changes in gene expression throughout the lifecycle of G. pallida, which provides important insights into the genes involved particularly in root invasion and establishment of the feeding site.

\section{Results and discussion}

\section{General overview of the G. pallida genome}

The genome of G. pallida was sequenced using a mixture of sequencing technologies (see Additional file 1: Table S1 for details), with reads from each technology assembled independently before merging, scaffolding and automated improvement (see Materials and methods, Additional file 1: Figure S1, Table S1 for details). This process produced a draft genome assembly of 124.7 $\mathrm{Mb}$ in 6,873 scaffolds of at least $500 \mathrm{bp}$, with an 
N50 scaffold length of $122 \mathrm{kbp}$ (Table 1, Additional file 1: Table S2), and with a GC content of $36.7 \%$ (Additional file 1: Figure S2). G. pallida is highly polymorphic [25], with at least $1.2 \%$ of sites being polymorphic in our experimental population alone, and its small size meant multiple individuals were pooled to generate sequencing libraries. The sequencing and assembly of highly polymorphic genomes remains challenging with current sequencing technology, even with a large amount of data from three complementary platforms. Current and future developments in both technology [26] and molecular biology techniques, such as methods for directly sequencing haplotypes [27] may perhaps facilitate the genome analysis of organisms such as G. pallida.

Comparison of the longest scaffolds from this assembly with the C. elegans genome shows no evidence of large-scale synteny or of significant conservation of gene order between the genomes. All of the 133 G. pallida scaffolds with at least five one-to-one orthologs to $C$. elegans have orthologs on more than one C. elegans chromosome (Figure 1A-C). This is in marked contrast to other nematode species at a similar or even greater phylogenetic distance from $C$. elegans such as the filarial nematodes B. malayi [17] and Loa loa [20], the plant parasitic nematode B. xylophilus [24] or even the very divergent Trichinella spiralis [28]. There is limited conservation of synteny between G. pallida and M. hapla of 216 G. pallida scaffolds with at least five one-to-one orthologs to $M$. hapla, six have orthologs to a single $M$. hapla scaffold, despite the draft nature of both assemblies, and some conservation of gene order within scaffolds is observed (Figure 1D, E). There is wider variation in karyotype within clade IV, of which G. pallida is a member, than other nematode clades, with haploid chromosome number varying within genera [29-32] and even within species [33] in this group but being stable at $n=6$ for all members of clade $\mathrm{V}$ [34]. The recombination rate in $M$. hapla is more than 50 -fold higher than the estimated rate for C. elegans [35]. Together, these data suggest that there has been a high rate of large-scale genome rearrangement in the evolutionary history of the lineage leading to G. pallida and other Tylenchids and, in particular, present the possibility that inter-chromosomal rearrangements may be more common in clade IV than elsewhere in the phylum. Confirmation of this will require higher-quality reference genomes for multiple members of this clade.

Although the G. pallida genome is fragmented, it still appears to be fairly complete, as approximately $85 \%$ of conserved eukaryotic genes can be identified in our assembly (Additional file 1: Table S2), and $81 \%$ of EST clusters map to the genome suggesting that at least that proportion of G. pallida genes are represented. The assembly is approximately $17 \%$ repetitive, with only around $1.8 \%$ showing similarity to transposable elements (Additional file 1: Table S3). No intact transposable elements were identified in the genome, confirming that most, or all, transposable elements are inactive. The longest LTR consensus is $5.3 \mathrm{~kb}$ long and the closest match is the Pao retrotransposon peptidase family protein from B. malayi.

\section{The protein-coding repertoire of $G$. pallida}

Using a combination of manual curation and transcriptomic evidence (see Materials and methods and Additional file 1: Table S4) a total of 16,419 genes were predicted in the G. pallida genome, intermediate between the gene counts reported for the two Meloidogyne genomes currently available. RNA-seq evidence from the extensive transcriptomic dataset we have generated (see below) supports

Table 1 Comparison of the Globodera pallida genome with selected other published nematode genomes

\begin{tabular}{|c|c|c|c|c|c|c|}
\hline & \multicolumn{4}{|c|}{ Clade IV } & \multirow{2}{*}{$\begin{array}{l}\text { Clade V } \\
\text { C. elegans }\end{array}$} & \multirow{2}{*}{$\begin{array}{l}\text { Clade II } \\
\text { Brugia } \\
\text { malayi }\end{array}$} \\
\hline & $\begin{array}{l}\text { Globodera } \\
\text { pallida }\end{array}$ & $\begin{array}{l}\text { Bursaphelenchus } \\
\text { xylophilus }\end{array}$ & $\begin{array}{l}\text { Meloidogyne } \\
\text { hapla }\end{array}$ & $\begin{array}{l}\text { Meloidogyne } \\
\text { incognita }\end{array}$ & & \\
\hline Estimated genome size $(\mathrm{Mb})$ & 100 & $63-75$ & 54 & $47-51$ & 100 & $90-95$ \\
\hline Haploid chromosome number & 9 & 6 & 16 & Varies & 6 & 6 \\
\hline Assembly length (Mb) & 124.7 & 74.6 & 53 & 86 & 100 & 95.8 \\
\hline Scaffolds $(n)$ & 6,873 & 1,231 & 1,523 & 2,817 & 7 & 8,180 \\
\hline Scaffold N50 (kb) & 122 & 1,158 & 84 & 83 & 17,493 & 94 \\
\hline Longest scaffold (kb) & 600 & 3,612 & 360 & 593 & 20,924 & 6,534 \\
\hline GC content & 36.7 & 40.4 & 27.4 & 31.4 & 35.4 & 30.5 \\
\hline Gene models $(n)$ & 16,419 & 18,074 & 14,420 & 19,212 & 20,056 & 18,348 \\
\hline Mean protein length (aa) & 361 & 345 & 310 & 354 & 440 & 312 \\
\hline CEGMA completeness & $81 / 85$ & $97 / 98$ & $95 / 96$ & $73 / 77$ & $100 / 100$ & $95 / 96$ \\
\hline (\% complete/partial) & & & & & & \\
\hline
\end{tabular}




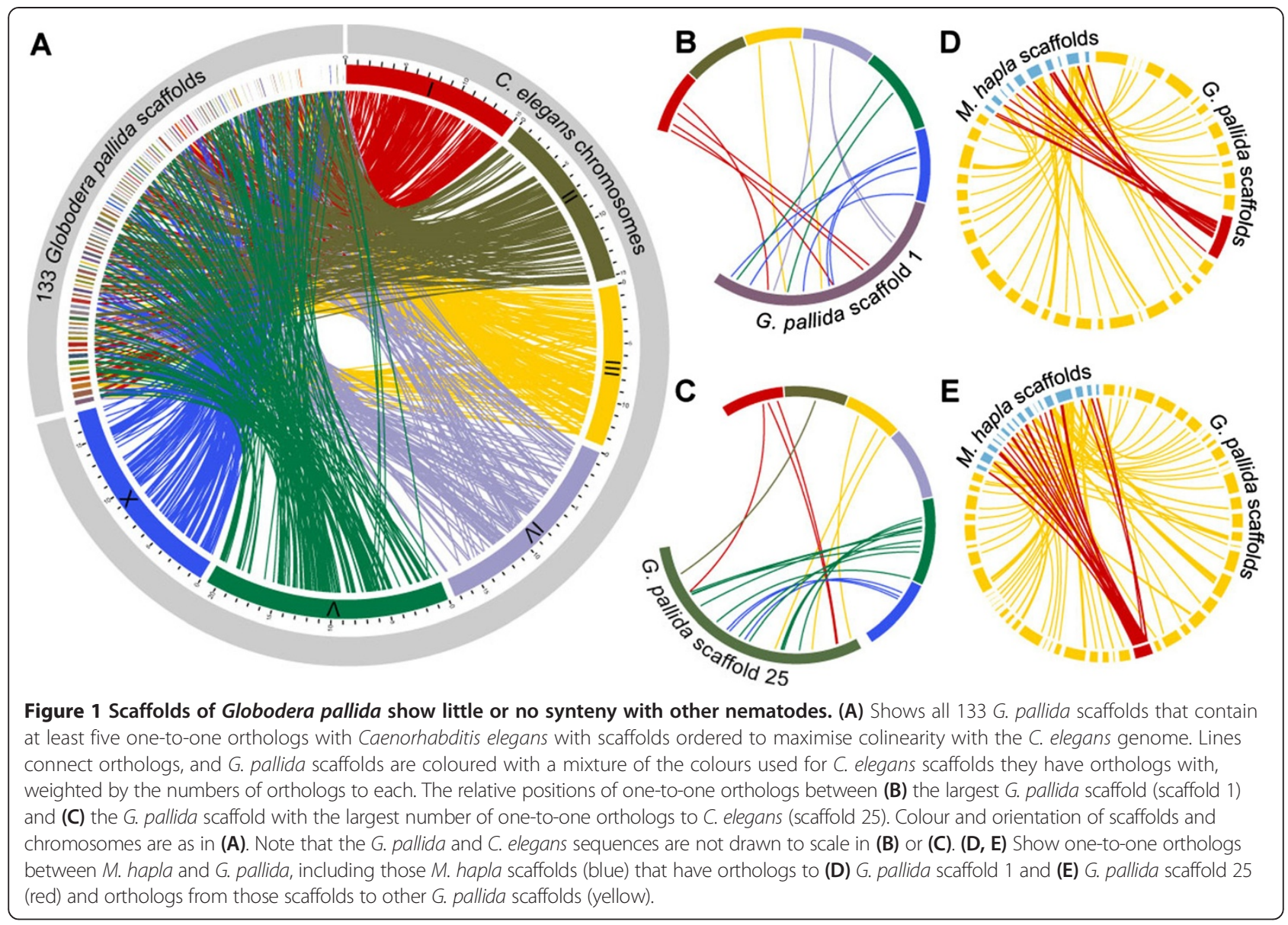

the transcription of a total of 15,329 (93.4\%) of the predicted gene models. At least one predicted protein domain or other InterPro feature was predicted for 14,139 of the gene models and 8,700 genes could be annotated with at least one Gene Ontology term.

A compact genome with high gene density may be characteristic of obligate parasitic lineages (for example, [36]). This is clearly the case for some plant parasitic nematodes; the $M$. hapla genome is the smallest published animal genome [21] and the tylenchid Pratylenchus coffeae is estimated to have the smallest genome of any animal $[37,38]$, but G. pallida does not follow this pattern. The significantly lower gene density of the $G$. pallida genome compared to other plant parasitic nematodes cannot be attributed to any single factor: on average, G. pallida has rather longer gene models than either Meloidogyne species, with more exons per gene and slightly longer introns (Additional file 1: Table S2), but both gene number and the proportion of the genome that is repetitive ( $12 \%$ in M. hapla, $36 \%$ in $M$. incognita, 22\% in B. xylophilus) are similar to those for the other published species, suggesting that a greater proportion of the G. pallida genome is non-repetitive, noncoding DNA.
Two different approaches were used to compare the G. pallida proteome with those of other nematodes (see Materials and methods). We found 6,714 gene families that contain at least one G. pallida protein, with 3,890 G. pallida genes not clustered into any family and 825 gene families unique to G. pallida. Functional analysis of both of these sets of G. pallida-restricted proteins using annotated GO terms (Additional file 1: Table S5) suggests that they are significantly enriched in membrane and extracellular proteins and proteins involved in carbohydrate and protein catalysis, which might play a role in the host-parasite interaction. Furthermore, there is enrichment of proteins potentially involved in activities related to mediating the complex life-cycle such as neurogenesis and neurotransmission, cuticle development and defence responses. The set of unique genes in G. pallida is also predictably enriched for proteins with little or no functional annotation, highlighting the need for further functional characterisation of G. pallida proteins. Among the largest gene families in the G. pallida genome are the SPRY domain proteins which include the SPRYSECs (secreted proteins containing a SPRY domain) and a family of proteins similar to the Heterodera glycines (soybean cyst nematode) effectors 4D06 and G16B09 (see below). In 
addition, a family of 474 G. pallida genes show similarity to a gene annotated as 'dorsal gland cell-specific expression protein' from the cereal cyst nematode Heterodera avenae (Genbank HM147943.1). These proteins are highly divergent and the consensus sequence has no homolog in C. elegans. The absence of functional data for any of these 'dorsal gland' proteins makes it difficult to analyse the significance of the expansion in G. pallida. However, RNAseq data show that some of the gene copies are highly expressed exclusively in the male samples. Some members of this gene family clearly have a different function in $G$. pallida compared to $H$. avenae; in situ hybridisation analysis of a small number of the G. pallida genes has shown that some are expressed in the digestive system (Additional file 1: Figure S3) with none of the sequences tested to date showing expression in the gland cells. However, the sequences chosen for analysis were selected on the basis of expression at the early stages of parasitism, rather than by similarity to the $H$. avenae sequence. Another expanded gene family, encoding glutathione synthetase proteins, is discussed in detail below.

Extensive genetic and genomic resources and a powerful molecular genetic toolkit make the free-living nematode C. elegans an important model system for studying a range of aspects of plant parasitic nematode biology $[39,40]$. Supporting this, the majority of G. pallida gene families contain C. elegans homologs (4,774 or $71 \%)$, although only $2,044 \mathrm{G}$. pallida genes have a one-one ortholog in C. elegans. However, many aspects of plant parasitic nematode biology cannot be studied in a freeliving system. This is reflected in the substantial genetic repertoire that G. pallida shares with related nematodes but that is not found in C. elegans: 331 gene families are uniquely found in the three tylenchid species (G. pallida and two Meloidogyne spp.) and another 121 families are found in B. xylophilus and tylenchids (Figure 2A). While 2,976 genes have one-one orthologs between G. pallida and $M$. hapla, we find substantial variation in gene content between G. pallida and the root-knot nematodes in total, G. pallida shares 741 gene families with other nematodes that are not present in either species of Meloidogyne. Indeed, G. pallida shares fewer gene families with M. incognita or M. hapla than with B. xylophilus (but more one-one orthologs with $M$. hapla), despite Meloidogyne and Globodera being more closely related. Phylogenetic reconstruction of the pattern of gene duplication and loss in the genomes of plant parasitic nematodes (Figure 2B) suggests this pattern is largely driven by differential gene loss between the cyst nematode and root-knot nematode lineages, although these figures could be somewhat inflated by the incompleteness of these draft genomes. Our findings confirm that the different molecular mechanisms of parasitism exploited by cyst and root-knot nematodes are reflected in a different complement of genes, particularly with respect to the repertoire of effector genes specifically involved in establishing and maintaining the host-parasite interface (see below), reflecting the independent origins of biotrophic parasitism in the two groups.

Organisation of genes into co-located and co-transcribed operons is a major feature of nematode genomes, with approximately $17 \%$ of C. elegans genes organised in operons [41]. Only 7\% of C. elegans operons appear to be conserved in G. pallida, but transcriptomic evidence suggests that $G$. pallida genes are arranged in operons (see Supplementary Results and Additional file 1: Figure S4). In C. elegans, polycistronic pre-mRNAs transcribed from operons are processed to form the mature mRNA by trans-splicing with spliced leader (SL) sequences. SL1 is trans-spliced to the first gene in an operon, while downstream genes are transspliced with SL2 [41]. Our RNA-seq data confirm that a diverse range of different SL types previously reported in $G$. rostochiensis [42] are also found trans-spliced to G. pallida transcripts. SL1-type sequences are found predominantly, but most genes appear to be promiscuously spliced to any of the SLs. In contrast to the situation in C. elegans [41], there is little evidence of a strong correlation in SL usage with distance between adjacent genes or expression pattern. The functional relevance of the diverse SL sequences in $G$. pallida is thus unclear.

\section{Transcriptome and differential gene expression in the G. pallida life cycle}

The relative expression of all G. pallida genes was determined by replicated Illumina RNA-seq across eight life stages. We examined unhatched J2 larvae within eggs, hatched invasive stage J2, adult males and parasitic individuals at early (7 and 14 days post infection (dpi)) and late (21, 28 and $35 \mathrm{dpi}$ ) stages post-infection of potato roots (Additional file 1: Table S4). The results reveal the dynamics of transcription across the G. pallida life cycle (Figure 3) with only 2,052 genes showing highly significant $\left(\mathrm{FDR}<10^{-5}\right)$ changes in expression between different life stages (see Additional file 2 for full lists of differentially expressed genes). Many of these differentially expressed genes encode hypothetical proteins $(1,417-57 \%)$, a significantly greater proportion than for non-differentially expressed genes. The number of genes expressed in each life stage varies (Additional file 1: Figure S5) with J2 larvae and adult males, the motile stages, showing high numbers of expressed genes. The number of genes expressed generally declines as the nematodes develop, with particularly low levels of gene activation during the development of adult females. A modest increase in the latest adult female stage presumably correlates with the development of embryos within the female. Transcript diversity follows a similar trend, except that the adult male transcriptome lacks diversity. 


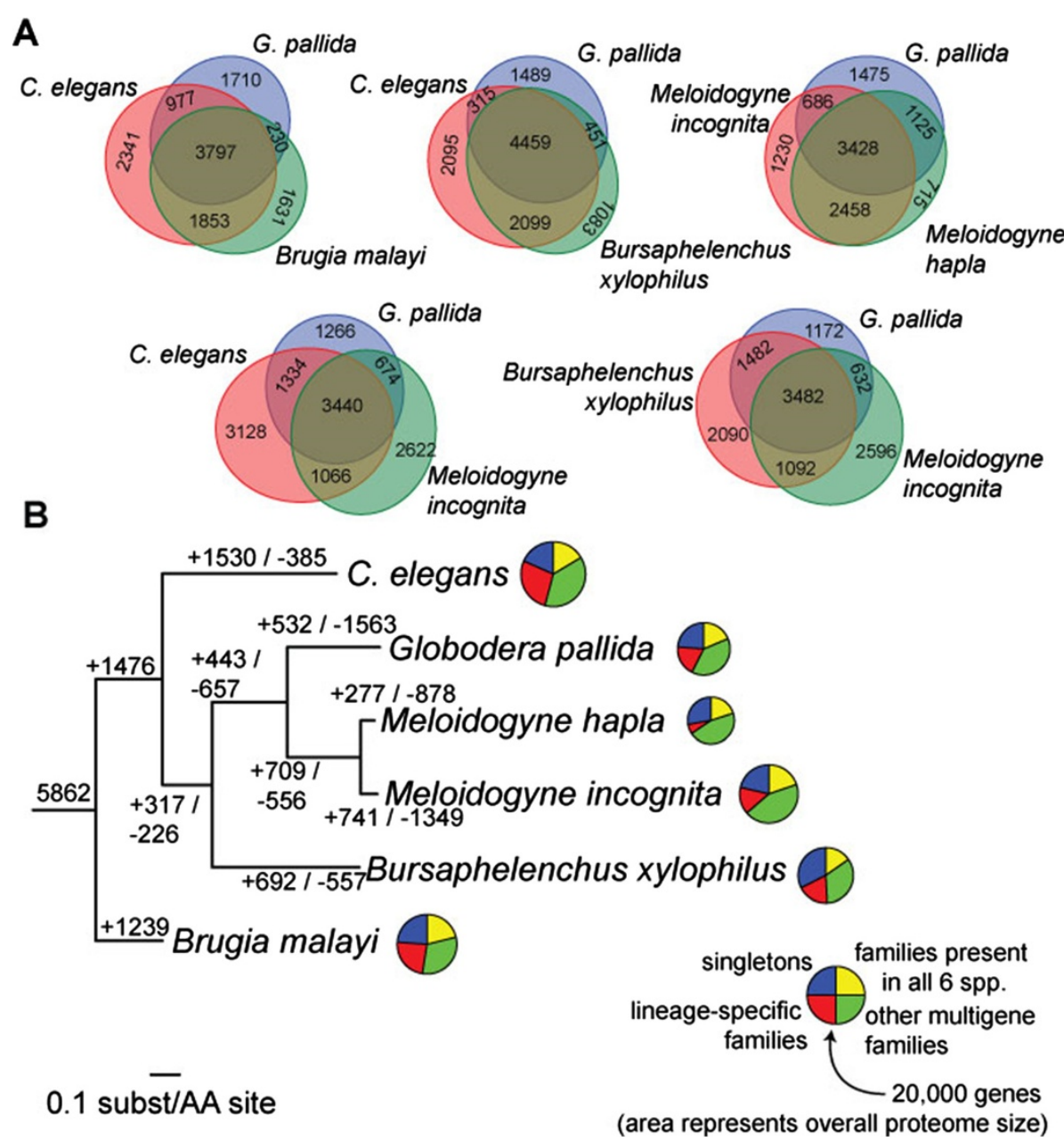

Figure 2 Comparative genomics of Globodera pallida and other plant parasitic nematodes. (A) Euler diagrams of shared presence-andabsence of gene families in plant-parasitic nematodes with published genome descriptions, the free-living model Caenorhabditis elegans and the spirurid animal parasite Brugia malayi. (B) Phylogenetic analysis of genome content. Tree shown is a maximum-likelihood phylogeny based on concatenated alignment of single-copy orthologs. Values on edges represent the inferred numbers of births (+) and deaths (-) of gene families along that edge. Note that our approach cannot distinguish gene family losses from gains on the basal branches of this tree, so for example the value of 1,476 gene family gains on the basal branch will include gene families lost on the branch leading to $B$. malayi. Pie charts represent the gene family composition of each genome - the area of the circle is proportional to the predicted proteome size, and wedges represent the numbers of proteins predicted to be either singletons (that is, not members of any gene family), members of gene families common to all six genomes, members of gene families present only in a single genome, and members of all other gene families.

It is dominated by a relatively small number of highly expressed transcripts, of which the major sperm protein has 10-fold higher expression than any other transcript. Other highly expressed transcripts in male nematodes are two of unknown function, a creatine kinase and one of the large 'dorsal gland cell specific' gene family discussed above. The transcriptome of adult females at 35 dpi is notably more diverse than expected from the low absolute number of different transcripts present.

Following stimulation of hatching in response to host root exudates, motile infective J2 larvae emerge from eggs within cysts, locate and then penetrate the potato root. A large-scale activation of transcription accompanies the hatching of J2s. Among the most enriched functional classes in this stage are 11 genes with poly-A transferase activity, most of which show similarity to poly-A polymerase gamma genes from other species that add poly-A to pre-mRNAs. This may reflect the need for large scale upregulation of transcription as the nematode emerges from dormancy. Carbohydrate metabolism is also upregulated in the transition to the hatched J2, including six cellulase genes and three pectate lyase genes presumably involved in host invasion and a chitinase that could be involved in the hatching process. The preparasitic J2 is protected neither by the eggshell nor within the host and is exposed both to pathogens and to plant defence molecules during initial root invasion. Correspondingly, a number of genes involved in defence 


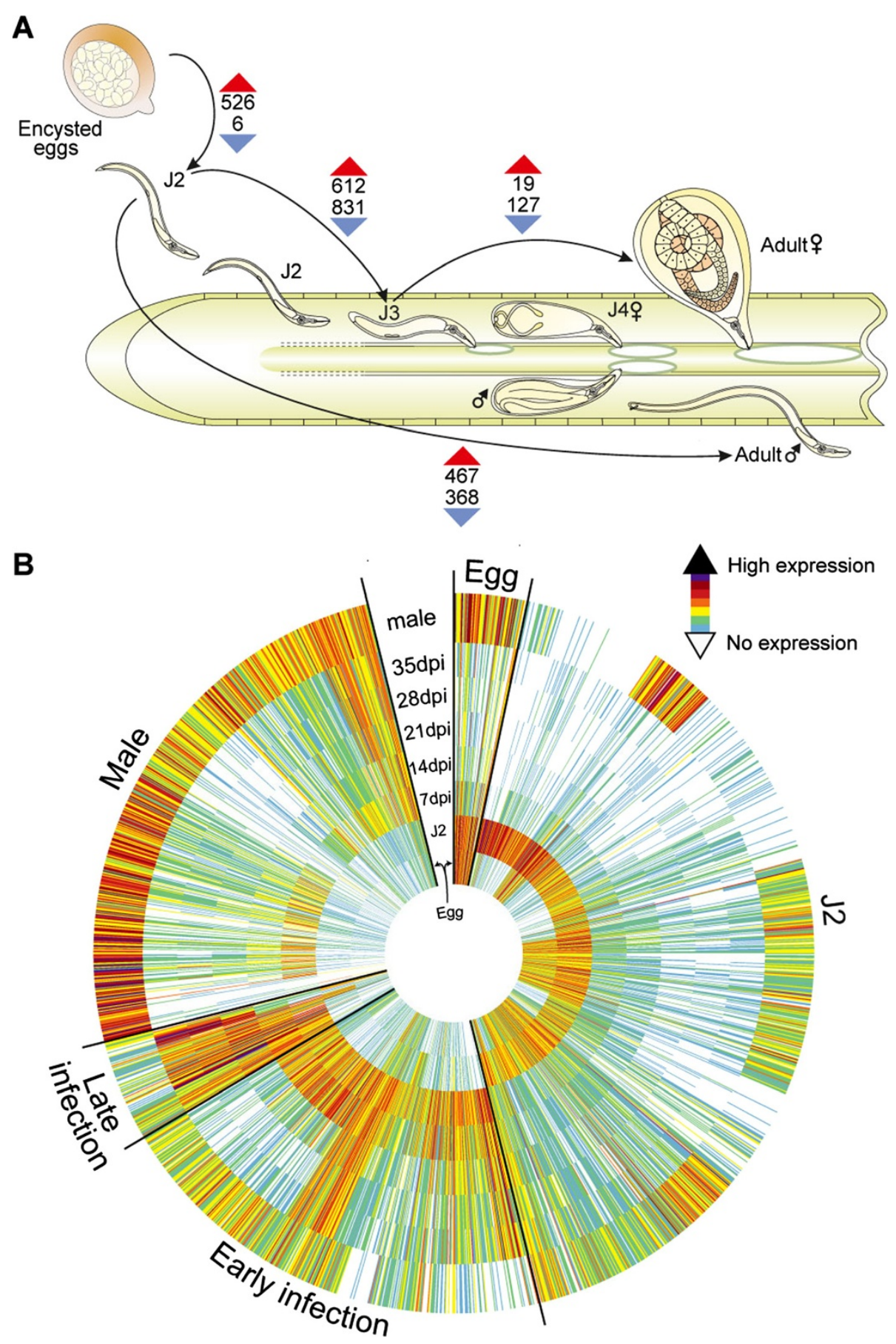

Figure 3 Transcriptional profiling of the G. pallida lifecycle. (A) Number of genes up- and downregulated between different stages in the $G$. pallida lifecycle. Labelled transitions are between egg and J2, J2 and early infection (7 and $14 \mathrm{dpi}$ ), early and late infection (21, 28 and $35 \mathrm{dpi}$ ) and J2 larvae and adult males. (B) Heatmap showing clustered expression profiles for all 2,052 differentially expressed genes. Genes are clustered to reflect similarity of expression profiles and then ordered by stage of highest expression, as labelled on the circumference of the figure.

responses are upregulated in this stage. In addition, genes upregulated in $\mathrm{J} 2$ are enriched for products that localise outside the cell, in the lysosome and the ER, possibly reflecting the secretion of proteins that mediate interactions with the host (effectors; see below).
After the syncytium is induced and feeding commences, the $\mathrm{J} 2$ nematode undergoes three moults to reach the adult stage. At 7 dpi both late parasitic J2 stage and early $\mathrm{J} 3$ larvae were present, whilst nematodes collected at 14 dpi were $\mathrm{J} 4$ females. The transition from 
infective J2 to these early parasitic stages is accompanied by the largest changes in gene expression during the lifecycle (Figure 3A). The clearest group of upregulated genes is a large set of glutathione synthetase genes these are discussed in more detail later. Other changes include the upregulation of many genes involved in lipid metabolism and proteolysis, in particular astacin proteases, and some cuticle collagens. These changes likely reflect the start of feeding by the post-parasitic J2 and moulting to the J3 and J4 female. Most downregulated gene classes appear to correlate well with transition from a motile free-living organism to sedentary parasitism. Expression of genes involved in signal transduction such as $\mathrm{G}$ protein-coupled receptors (GPCRs), GPCR signalling through cyclic nucleotides, sodium and potassium ion transport, neurotransmitter metabolism and oxygen transport is reduced. This interpretation is re-enforced by the downregulation of homologs of a number of genes with well-understood functions in neurotransmission and chemotaxis in C. elegans (egl-3, osm-3 and a EXP-family potassium channel [43-45]).

The female worms are adult by $21 \mathrm{dpi}$, and their continued development through to $35 \mathrm{dpi}$ is accompanied by enlargement and swelling to a spherical shape. Embryos develop within fertilised females and the J1 larvae undergo the first moult inside the eggs contained within the female body. Despite this development, we find relatively few changes in expression between the early and late parasitic stages. Upregulated genes are enriched for functions in lipid transport and chitin catabolism as lipid stores are provided to the developing embryos and chitin is laid down in egg shells. The most highly expressed genes in both 28 and 35 dpi samples encode vitellogenin and a number of cuticle collagens. These reflect the accumulation of yolk proteins within oocytes and the subsequent synthesis of cuticular material for the J1 and J2 nematodes that develop within the eggs.

The sexual fate of cyst nematodes first becomes apparent at the end of the parasitic J2 stage, shortly before the moult to J3. Males feed until the end of the J3 stage before a motile, vermiform adult male develops within the J4 cuticle, then emerges and leaves the root to locate and fertilise females. Although some genes associated with motility are shared between males and pre-parasitic $\mathrm{J} 2 \mathrm{~s}$, the transcriptome of males is very distinct from both the early parasitic stages and the J2. Eight $\alpha, \alpha$-trehalase genes, which encode the enzyme responsible for hydrolysing trehalose to produce glucose, are upregulated in males. While these could be involved in mobilising stored trehalose for energy in the motile stage, it is not clear why this should differ between $\mathrm{J} 2$ and adult males. However, trehalose plays a number of different roles in nematodes and is particularly enriched in reproductive tissues [46]. Upregulation in males of genes involved in proteolysis, ubiquitination and other aspects of protein metabolism such as glycosylation and phosphorylation might reflect the protein turnover that presumably accompanies a change back to a free-living lifestyle. Changes in lipid metabolism genes were also consistent with this; the adult male does not feed and relies on the mobilisation of stored lipid. A number of proteins that localise to nucleosomes were significantly enriched, perhaps suggesting some chromatin remodelling or cell divisions associated with production of sperm. Several expression changes, such as a homolog of a testis specific protein kinase and major sperm protein (MSP) are clear markers for male reproductive machinery - indeed, the latter is the most highly expressed gene in the male samples.

Complementing the pairwise comparisons between lifecycle stages, clustering of gene expression profiles clearly demonstrated that changes in the transcript profiles accurately reflect changes in G. pallida biology across the life cycle. For example, the J2 and adult male are the only mobile stages of the nematode. A cluster of 154 genes was identified as being specifically upregulated in both of these life stages; analysis of gene ontology terms significantly enriched in this cluster showed that all were related to neuromuscular function (Additional file 1: Figure S6A). Similarly, a cluster of 59 genes upregulated in parasitic stages was significantly enriched for gene ontology terms relating to cuticle synthesis and protein digestion, reflecting the fact that these life stages are actively feeding and undergoing repeated moults (Additional file 1: Figure S6B).

\section{Genomic insights into the mechanisms of plant parasitism in Globodera}

G. pallida is a complex, biotrophic pathogen that has intimate interactions with its host. These interactions are mediated by effector proteins (also termed parasitism proteins) responsible for a variety of processes: modification of the host cell wall during invasion, induction of the feeding structure, manipulation of host metabolism for the nutritional benefit of the nematode and suppression of host defence responses to ensure maintenance of the feeding site. Effectors have previously been identified from plant parasitic nematodes through EST sequencing (for example, [47]), expression profiling [48] and through sequencing of mRNA extracted from aspirated gland cell cytoplasm [49], each followed by in situ hybridisation to confirm gland cell expression of the candidate genes. Analysis of the G. pallida genome showed that it contains orthologs of many of the effectors previously identified from other cyst nematodes (Additional file 1: Table S7). However, with the exception of enzymes that degrade the plant cell wall and chorismate mutases (see below), there is almost no overlap between effectors identified from root-knot nematodes and cyst nematodes. These findings 
are consistent with the idea that biotrophic interactions with plants have arisen independently in root-knot and cyst nematodes (for example, [50]). Just two candidate effector types from G. pallida (GPLIN_000604400 (similar to GPLIN_000555600) and GPLIN_001475500) have matches in root-knot nematodes and the first of these, similar to $M$. incognita effector accession number AY135365, is also present in (non-biotrophic) migratory endoparasitic nematodes (for example, P. coffeae - A. Haegeman, pers comm) but is not present in non-plant parasitic species. This effector may have a conserved role in the infection of plants by nematodes.

Plant parasitic nematodes are known to possess a variety of plant cell wall modifying enzymes, many of which have been acquired by horizontal gene transfer from bacteria (reviewed by [51]). G. pallida has a complex array of cell wall modifying enzymes (Additional file 1: Table S8) with a broadly similar repertoire of enzymes to that described for M. incognita [22], except that G. pallida lacks GH28 polygalacturonases, and the GH53 arabinogalactan endo-1,4 beta galactosidases may be specific to cyst nematodes as they are present in G. pallida and Heterodera schachtii [52] but are absent from $M$. incognita and $M$. hapla. In addition four genes (GPLIN_000483300, GPLIN_000949800, GPLIN_000950300 and GPLIN_001068900) that could encode secreted GH32 fructosidases are present in G. pallida. These enzymes could metabolise sucrose into fructose and glucose and are similar to the invertases previously described from M. incognita and M. hapla. Globodera pallida also contains two putative chorismate mutases that are likely to have been acquired by horizontal gene transfer from bacteria [53]. Similar genes have been described from a range of plant parasitic nematodes. In addition, although they are not effectors, two genes potentially involved in Vitamin B6 biosynthesis are present in cyst nematodes that are likely to have been acquired from bacteria [54]. These two sequences are present in G. pallida, are located side by side on the same scaffold (Gpal_scaffold_166) in the assembly and show almost identical expression profiles.

Effector proteins are secreted from two sets of gland cells (dorsal and subventral), through the stylet and into the host. These cells show distinct developmental profiles. The subventral glands are large and full of secretory granules in preparasitic and early parasitic J2s, but contain fewer secretory granules during parasitism before becoming active again in adult males. In contrast, the dorsal gland cells are smaller in J2 but increase in size and activity throughout the sedentary parasitic stages [55]. The expression of effectors we have identified reflects this, with particular families showing peak expression in either the $\mathrm{J} 2$ or early infection stages (Figure 4A). Effectors identified as being J2-specific included those for which there is experimental verification of subventral gland cell expression in G. pallida, such as the chorismate mutases [53]. Several plant cell walldegrading enzymes were expressed in both $\mathrm{J} 2 \mathrm{~s}$ and in males, stages that need to enter and escape from the host root, respectively, and reflecting experimentally verified expression profiles (for example, [56]). Two additional effectors of unknown function also shared this expression profile. Many other effectors showed elevated expression in parasitic stages and these included G. pallida orthologs of effectors known to be dorsal gland specific in other plant parasitic nematodes (for example, $[49,57])$.

Some of the G. pallida effectors are present in large multigene families. One family of proteins, similar to $H$. glycines effectors 4D06 and G16B09, has approximately 40 members in G. pallida (Additional file 1: Table S7). Over 30 of these are significantly upregulated in parasitic stages. However, perhaps the most significant example of an expanded gene family is provided by the SPRY domain proteins, a family that includes the SPRYSECs: a family of known effector proteins in G. pallida [47] and G. rostochiensis [58] (see Additional file 1: Table S9). One G. rostochiensis SPRYSEC (G. rostochiensis Sprysec 19) is known to interact with a resistance protein [58] and one G. pallida SPRYSEC (RBP1) has been identified as the avirulence factor recognised by the resistance protein Gpa2 [59], suggesting that this gene family may be under strong selection pressure to evade recognition by the host. While all nematodes examined to date have SPRY domain containing proteins, these are typically not secreted and the 299 G. pallida proteins predicted to have one or more SPRY domains represent an enormous expansion over that found in other nematodes (for example, C. elegans, B. xylophilus and M. incognita have 8, 12 and 27, respectively). Some of the G. pallida SPRY domain proteins are closely related to homologs from B. xylophilus and M. incognita and are constitutively expressed, but most form part of a large lineage-specific expansion of proteins, with many showing peaks of expression in J2s (Figure 4B). All of the secreted SPRY domain proteins (a minimum of 37 sequences) are included in this expansion.

A bioinformatic approach combining the genome and transcriptome information was also used to identify novel candidate effectors from G. pallida. Secreted proteins that are significantly upregulated in J2s (as compared to eggs) or in nematodes at $7 \mathrm{dpi}$ (versus J2) were first identified and BLAST was then used to remove proteins that clearly have another functional role (for example, collagens and digestive proteases). The results of this analysis are summarised in Additional file 1: Table S10. A total of 117 proteins were identified that met the criteria and represent potential novel effectors; some of these genes were previously identified as potential novel effectors in an analysis of G. pallida ESTs [47]. 


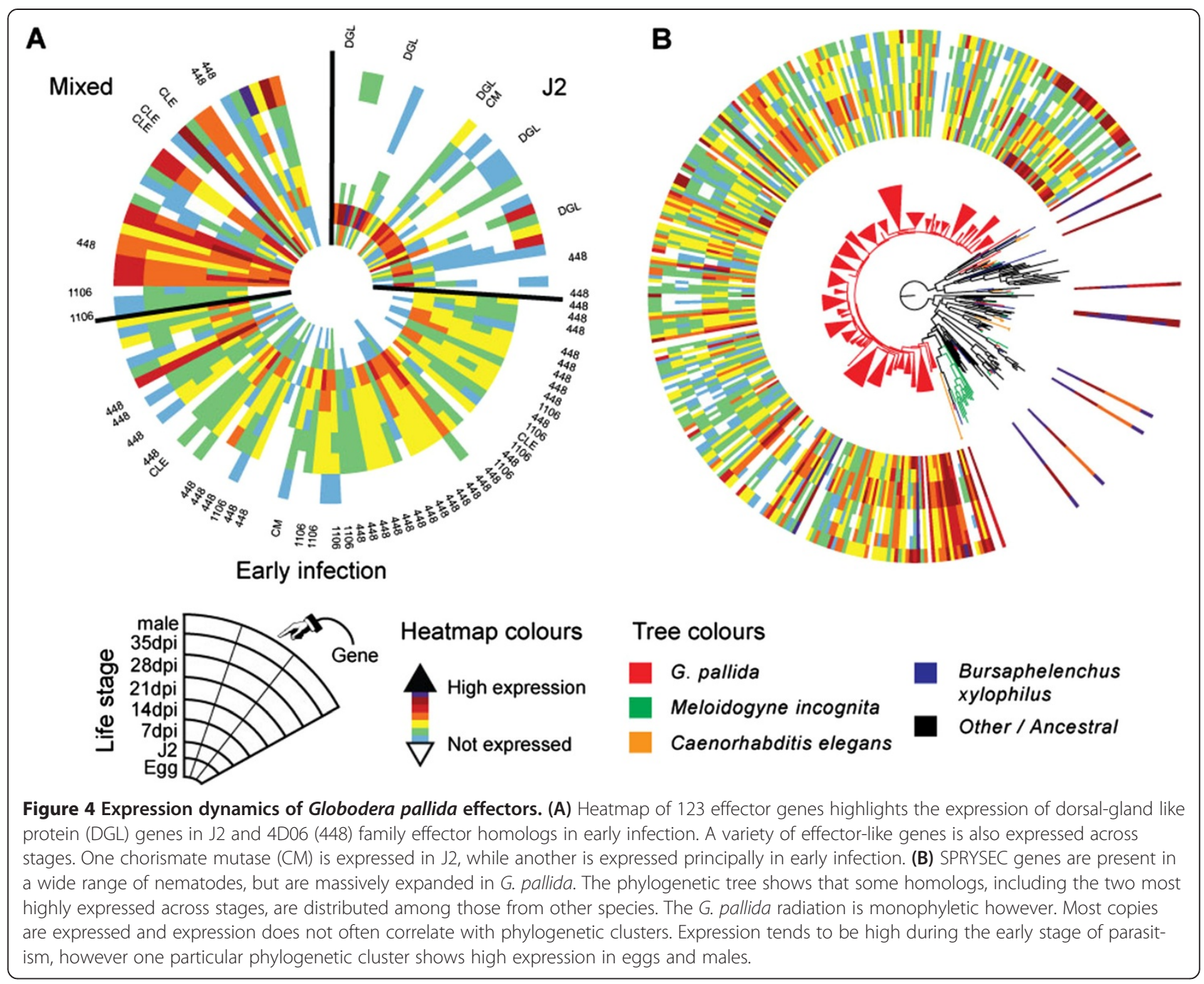

\section{Protection against plant defences and other} environmental stresses

Some plant defence responses involve production of reactive oxidative radicals [60] and plant-parasitic nematodes are likely to have evolved specialised systems to neutralise these cytotoxic responses. A key step in this process is the generation of hydrogen peroxide, catalysed by superoxide dismutase (SOD) enzymes and the G. pallida genome contains an expanded family of 10 SOD genes (Additional file 1: Table S11). These enzymes mostly show homology to C. elegans $\mathrm{Cu} / \mathrm{Zn}$ sod- 1 involved in stress responses [61]. Cyst nematode J2s migrate intracellularly through host roots, causing considerable tissue damage and necrosis, whereas J2s of root-knot nematode migrate intercellularly, eliciting little response from the host. This difference may account for the increased repertoire of G. pallida genes involved in neutralisation of the oxidative free radicals produced by the plant. As expected, G. pallida also contains sets of genes involved in the rapid breakdown of the cytotoxic hydrogen peroxide released during this process, including catalase, peroxiredoxin and glutathione peroxidase genes.

These redox processes all require glutathione and $G$. pallida contains 52 glutathione synthetase genes compared to typically one to four copies in other nematodes. Even more surprisingly, about one-quarter of the genes contain a signal peptide and these all show a peak of expression in the early parasitic stages $(7 \mathrm{dpi})$. Those genes with a predicted cytoplasmic location tend to be expressed more stably throughout the nematode lifecycle (Figure 5). Previous work has shown that, like animal parasites, potato cyst nematodes secrete antioxidant proteins on to their surface including peroxiredoxins [62] and glutathione peroxidase [63] and the expanded repertoire of glutathione synthetase genes in G. pallida may produce glutathione to act as co-factors for these proteins. Moreover, glutathione plays a range of functions in plants, including involvement in signalling and regulation of plant development [64], and is essential for 


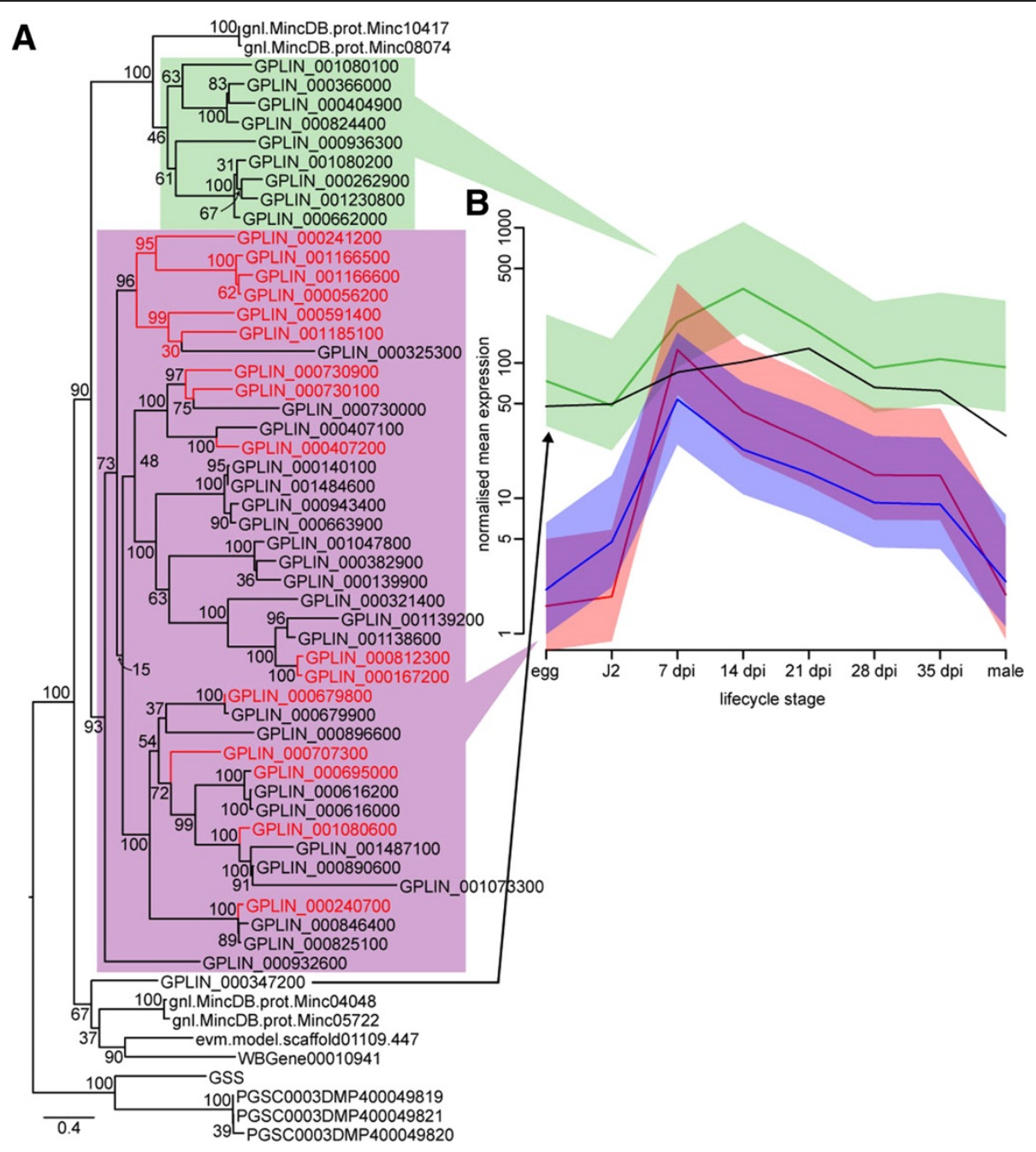

Figure 5 Phylogeny and expression of glutathione synthetase genes in G. pallida. (A) Phylogeny of all G. pallida glutathione synthetase genes that can be aligned over at least 200 bp. Non-G. pallida sequences are from Meloidogyne incognita, Bursaphelenchus xylophilus, Wuchereria bancrofti and from mammals. Red sequences are predicted to have signal peptides. (B) Different clades of these genes show different expression dynamics. The single-copy outgroup sequence, apparently shared by all nematodes, is constitutively expressed across the lifecycle (black line). Members of the clade shared with some $M$. incognita sequences (green) show a peak of expression at 14 dpi, while the G. pallida-specific expansion (purple in panel A) shows a peak of expression at 7 dpi, a pattern more pronounced in copies predicted to have signal peptides (red) than those without (blue). Lines are mean expression across gene copies for each lifecycle stage; shading covers a 99\% exponential confidence interval for the mean.

reproduction and proper development of nematodes during their infective stage in the host. Depletion of glutathione in host plants reduces the availability of starch and sugars to M. incognita during parasitism by this nematode, resulting in fewer egg masses and altered sex ratio [65]. While glutathione levels are usually controlled by regulation of $\gamma$-glutamylcysteine synthetase, which catalyses the first committed step in glutathione synthesis [66], we propose that G. pallida may have evolved to produce high levels of glutathione both internally and within the host cells to stimulate the plant to provide the nematode with adequate carbohydrate nutrition.
Since G. pallida feeds only from the host plant, it is unlikely to encounter as wide a range of xenobiotics as free-living nematodes, although its host plants produce a number of toxic tropane alkaloids [67]. This may explain a vast reduction in predicted genes encoding enzymes and transporters involved in costly and specialised cellular metabolism and detoxification of such compounds compared to those found in C. elegans (see Additional file 1: Table S11). There are fewer genes involved in all three phases of detoxification of secondary metabolites [68] in G. pallida. There is a reduced number and diversity of cytochrome P450 genes (Phase I), fewer glutathione and UDP-glucuronosyl transferases (GSTs and 
UGTs) (Phase II) and a reduction in $\mathrm{ABC}$ transporters (Phase III). The CYP-35 subclass of CYP450 genes (which is particularly associated with xenobiotic metabolism in C. elegans) is completely absent in G. pallida while the CYP-33 subclass, associated with lipid storage and regulation of endogenous processes [69], is conserved and contains the majority of the G. pallida genes. Two CYP-33 genes are highly expressed in $\mathrm{J} 2$ compared to parasitic stages and may play a role in lipid regulation in the non-feeding pre-infective stage. Most of the GST genes in G. pallida belong to the Sigma class, as found for C. elegans and M. incognita [70]. The parasitic lifestyle of G. pallida means that it is also likely to directly encounter a reduced array of pathogens compared to the free-living C. elegans. We find that most immune signalling pathways appear to be highly conserved between $G$. pallida and other nematodes (Additional file 1: Table S12), with the exception of some members of the Toll pathway which is the pathway responsible for recognising different types of pathogens. In contrast, immune effectors such as lysozymes, C-type lectins and chitinases are much less abundant in G. pallida (and M. incognita [22]) than in C. elegans, and whole classes of antibacterial and antifungal genes, including those encoding antibacterial factors (abf), saposin-like proteins (spp), fungusinduced proteins $(f i p)$ and the anti-bacterial neuropeptidelike proteins (nlp24-33) are entirely absent.

\section{Nuclear hormone receptors}

Nuclear hormone receptors (NHRs) are a conserved family of ligand-binding transcription factors that regulate diverse physiological processes including metabolism, development, reproduction and immune responses. The receptors bind to an extensive range of lipophilic molecules including fatty acids, vitamins, steroids and xenobiotics, providing a direct link between these ligands and the expression of target genes. They are therefore likely to play a central role in the regulation of lipid metabolism and responses to plant-host defences. The family has undergone a massive expansion to 284 genes in C. elegans, the majority of which belong to the group of nematode-specific supplementary NHRs (SupNRs) [71]. G. pallida has only 54 NHRs (Additional file 1: Table S13), similar to the predicted repertoire in mammals [72]. Most of the G. pallida NHR genes are SupNRs that share little homology between nematode species. The lack of conservation between SupNR members in G. pallida and M. incognita would suggest that expansion of SupNRs has proceeded independently in the two species. An exception is the homolog to $n h r-88$, which regulates lipid storage in C. elegans and is highly expressed in J2s, possibly reflecting the mobilisation of lipid reserves at this stage. One G. pallida SupNR conserved only in C. elegans ( $n h r-25)$ is highly expressed during the early stages of infection and may regulate responses to neutralise plant cytotoxic activity.

\section{Sex determination and diapause}

We investigated the conservation in G. pallida of two developmental signalling pathways that are well understood in C. elegans and underlie key aspects of G. pallida biology. Sex determination in C. elegans is controlled genetically [73], while in G. pallida the sex of each nematode is environmentally influenced, with the food supply determining the sexual fate of developing J2 larvae. Individuals that induce a larger feeding site are more likely to develop into females [15,74-76]. This leads to a greater proportion of males when infection levels are high, and is exploited by plants, as some resistance genes operate by restricting development of the feeding site resulting in fewer of the more damaging females (for example, [15,77]). The C. elegans sex determination pathway is only poorly conserved in $G$. pallida, with clear orthologs found only to C. elegans fem-2, mag-1 and mog-1, together with G. pallida genes showing some similarity to laf-1, gld-1, tra-1 and fem-1. Globodera pallida is a host-specific pathogen that must coordinate its life cycle with the availability of a suitable host plant. Like many nematodes, including C. elegans, G. pallida has a survival stage which is adapted for longterm survival in the absence of a food source. The survival stage in G. pallida is the unhatched J2, which can survive in cysts for up to 30 years in the absence of a host [78], and is functionally similar to the dauer larva of C. elegans $[79,80]$. However, we find relatively poor conservation of most of the four signalling pathways that control the developmental decision to enter and leave the dauer stage [81] (Additional file 1: Table S14) and not all of the conserved genes show the expected peak of expression either in the egg or the mature female within which the juveniles are developing (Additional file 1: Figure S7). These signalling pathways appear to be a mosaic of conserved genes and genes missing from G. pallida, underlining how variable developmental pathways can control development of quite conserved morphology as shown in other nematodes (for example, see [82] for review), but functional studies will be needed to understand development and sex determination in G. pallida.

\section{Conservation of the RNAi pathway in G. pallida}

RNA interference (RNAi), the process by which double stranded RNA (dsRNA) initiates homology-dependent transcriptional gene silencing, was first described for $C$. elegans [83] where it has become an invaluable tool for functional analysis. Since it was first demonstrated that RNAi could be used to silence genes in J2 cyst nematodes [84] it has been exploited in a range of plant parasitic nematode species both in vitro, as a tool for 
functional genomics, and in planta as a strategy for transgenic control. While the technique seems more reliable than for many animal parasitic species [85], inconsistent levels of gene silencing have been reported and the molecular details of the pathways involved have not been elucidated.

A recent study identified 77 C. elegans proteins involved in the five key stages of the RNAi pathway [86]. We present a complete catalogue of the repertoire of $G$. pallida genes involved in these processes (Additional file 1: Table S15). Like other parasitic nematodes studied, G. pallida contains genes involved in most aspects of the C. elegans RNAi pathway, but has fewer genes overall and is particularly deficient in those encoding proteins responsible for uptake of dsRNA and spreading dsRNA between cells to enable systemic RNAi. Many features of the G. pallida repertoire appear to be widely conserved in both plant- and animal-parasitic nematodes, such as the conservation of $r s d-3$, thought to be involved in the intercellular distribution of dsRNA following uptake [87] and a reduced total complement of AGO genes in comparison to C. elegans [86]. Indeed, in most respects, the RNAi pathway in G. pallida appears similar to those described for M. hapla and M. incognita [86], including similar complements of RNAi inhibitors and nuclear RNAi effectors. G. pallida also shares an expansion of genes homologous to ego-1 RNA-dependent RNA polymerase (RdRP), and expansion of particular AGOs with B. xylophilus [24]. Unique features of the G. pallida RNAi gene complement include the apparent loss of the Dicer-related helicase, $d r h-1$, and loss of a number of components of the C. elegans RISC complex, although these remain poorly characterised. The similar RNAi pathways found in G. pallida and other parasitic nematode species lack several important components of the C. elegans RNAi machinery, suggesting that alternative proteins, or proteins only poorly conserved at the sequence level may be behind the effective, systemic RNAi possible in these species (for example, $[84,88,89]$ ).

\section{Neurotransmission}

Despite a relatively simple structure, the nematode nervous system is able to service complex and subtle behavioural responses, accomplished by sophisticated signalling with a diverse array of signalling molecules such as neuropeptides and inherent heterogeneity of receptors for classical neurotransmitters. For example, nematode receptors for acetylcholine (ACh) and glutamate consist of distinct subunits that can assemble in multiple combinations to provide a high degree of receptor plasticity. Beside its inherent interest, the nematode nervous system is a particular target for chemical control methods [90], so greater understanding of the available target molecules may help in the rational design of new nematicides. We present a comprehensive analysis of G. pallida neurotransmitter receptors (Additional file 1: Table S16), genes involved in the synthesis, transport and metabolism of neurotransmitters (Additional file 1: Table S17) and genes encoding neuropeptide precursors (Additional file 1: Tables S18, S19; see Supporting Results in Additional file 1 for a detailed description). Genes responsible for the production and utilisation of the neurotransmitters $\mathrm{ACh}$, serotonin, dopamine, tyramine, octopamine, glutamate and gammaaminobutyric acid (GABA) are all present in G. pallida with a very similar complement to $C$. elegans. Similarly, most subtypes of neurotransmitter receptors found in $C$. elegans are present in G. pallida, but there are differences in the complement of particular types. G. pallida has a somewhat smaller repertoire of nicotinic acetylcholine receptors (nAChRs) than C. elegans, with a particularly reduced number of ACR-16 class receptors. It does, however, contain members of each of the five distinct groups of nAChRs [91] and operon organisation of some of these genes (acr-2 and acr-3, des-2 and deg-3) appears conserved.

\section{Conclusions}

Globodera pallida is an economically important pathogen of potatoes, as well as a key model system for understanding the biology of cyst nematodes, one of the most important groups of plant pathogens worldwide. The analysis presented here for G. pallida is, to our knowledge, the first description of the genome organisation and content of a cyst nematode, complementing the previously characterised genomes of root-knot nematodes. We describe gene expression changes throughout the $G$. pallida lifecycle, including eight different life-stages among the most comprehensive data available for any parasitic nematode. The combined genome and transcriptome dataset represents a vital platform in understanding the biology of cyst nematodes, enabling generation of testable hypotheses about gene function and offering valuable insight into many key processes associated with the parasitic lifestyle.

Biotrophic plant parasitism has arisen independently in cyst and root-knot nematodes, with convergent evolution resulting in the two sedentary endoparasites that induce functionally similar feeding sites. We describe the repertoire of known effector gene families, and exploit our expression data to predict novel effector classes, confirming the distinctive nature of biotrophic parasitism in cyst nematodes. The set of G. pallida effectors is strikingly distinct from those previously described in root knot nematodes. Further investigation of this complement of effectors is likely to reveal the genetic basis of the detailed differences in the induced feeding sites of cyst and root-knot nematodes, the greater host specificity of cyst nematodes and the virulence characteristics 
of G. pallida towards different host cultivars. This knowledge will help inform new technologies to control $G$. pallida, and we have described the genetic basis of key nematode biological processes such as neurotransmission, sex determination and diapause that are targets of intervention for the development of new nematode control or management strategies. For example, heterologous expression of G. pallida receptors will now be possible to enable functional characterisation and testing of specific chemicals aimed at their disruption. The RNAi pathway is of interest as a target for control and is also a key technology both in functional genomics and in development of transgenic plants that express dsRNAs to target genes essential to the nematode.

Our transcriptome data allow us to go well beyond a genomic 'parts list' of proteins and genetic elements that underlie organism function, as the temporal pattern of gene expression gives vital clues to the roles genes play in different processes. The next step is to fully understand how these parts function and interact to cause plant parasitism. Genomic data are becoming key in the fight against a number of groups of plant pathogens [92-94]. The publication of a cyst nematode genome sequence opens the door to applying post-genomic technologies to this important group.

\section{Materials and methods}

\section{Biological material and nucleic acids extraction}

The G. pallida population 'Lindley', a standard Pa2/3 pathotype held at the James Hutton Institute, Dundee, UK [95] was used to provide source biological material for both DNA and RNA extraction. Cysts were extracted after 10 to 12 weeks of growth of nematodes on host potato plants, and pooled eggs from multiple cysts used for genomic DNA isolation. Total RNA was extracted from eggs of G. pallida, freshly hatched J2s, parasitic stages at 7, 14, 21, 28 and $35 \mathrm{dpi}$, and adult males. Two RNA samples of 5 to $10 \mu \mathrm{g}$ were produced for RNA-seq of each life-stage, with each replicate sample derived from pooled nematodes collected on multiple occasions. See Supporting Methods in Additional file 1 for full details of all methods.

\section{Genome sequencing and assembly}

We assembled a draft sequence of the G. pallida genome based on data from a mixture of sequencing technologies. Additional file 1: Table S1 gives full details of the sequencing libraries used. Genomic and transcriptomic sequence data were generated using largely standard molecular biology methods, except that wholegenome amplified (WGA) material was used to generate sufficient DNA for some libraries (see Supporting Methods in Additional file 1). However, analysis of WGA DNA sequence revealed that the amplification technique used had introduced large numbers of inverted repeats into the amplified material. The vast majority of the sequence data generated from this material therefore had to be discarded. Sequence reads from each technology were initially assembled independently using assembly algorithms most suited to the typical coverage and read length of each, followed by a process of merging, scaffolding with long-insert read pair data from the Roche and Illumina platforms and improvement by automated gap-filling and error correction. G. pallida is an obligate parasite, and so cannot be cultured axenically, and highly inbred material is not available. The initial assembly thus contained contamination from both fungal and bacterial sources, as well as a small number of contigs likely to represent haplotypic variants of other contigs in the assembly, which were removed in a conservative approach. Full details of the assembly construction and cleaning are presented in the Supporting Methods section in Additional file 1.

\section{Protein coding gene prediction, functional and comparative annotation}

Protein-coding genes were predicted using Augustus [96], trained with manually curated gene models and using evidence from mapped RNA-seq data. Functional annotation information came from sequence similarity searches, Interproscan [97] and Blast2GO [98] together with manual annotation and additional approaches specific to particular functional categories. Comparative analysis of protein-coding genes between nematode genomes was based on OrthoMCL [99] (called gene families above) and a stand-alone version of the OMA algorithm [100] (called one-to-one ortholog groups). Additional details are presented in the Supporting Methods section in Additional file 1. A total of 2,966 EST clusters were obtained from NEMBASE4 [101] and mapped against the G. pallida genome assembly using nucmer version 3.07, keeping hits with at least $95 \%$ nucleotide identity.

\section{Gene expression analysis}

Analysis of RNA-seq data was based on counting reads mapping to each protein-coding gene model. Values for relative expression between stages and counts of expressed genes were based on mean RPKM values across the two replicate samples for each life stage. Descriptions of genes as being up- or downregulated between life stages are based on statistical analysis of RNA-seq data using pairwise tests for significant differential expression between stages. We also used modelbased clustering of genes to identify sets of genes with similar gene expression dynamics across the stages. See Supporting Methods in Additional file 1 for full details. 


\section{Data access}

Sequence data described in this paper have been submitted to the Genbank database. Data and annotation have been submitted to Wormbase and Genbank. The G. pallida genome assembly and functional annotation is available from ftp://ftp.sanger.ac.uk/pub/project/pathogens/ Globodera/pallida and via GeneDB at http://www.genedb. org/Homepage/Gpallida. Raw sequence reads are available from the ENA SRA as listed in Supporting Information.

\section{Additional files}

Additional file 1: Supporting Methods, Results, Figures and Tables.

Additional file 2: Tables of genes with significant differences in expression between life-stages of Globodera pallida.

\begin{abstract}
Abbreviations
ABC: ATP-binding cassette; ACh: Acetylcholine; AGO: Argonaute protein; CYP: Cytochrome P450; dpi: Days post infection; ER: Endoplasmic reticulum; GPCR: G protein-coupled receptor; GST: glutathione-S-transferase; J1 to J4: First- to fourth-stage juvenile; nAChR: Nicotinic acetylcholine-gated receptor; NHR: Nuclear hormone receptor; PCN: Potato cyst nematode; RISC: RNA-induced silencing complex; RNAi: RNA interference; SL: Spliced leader; SOD: Superoxide dismutase; SPRYSEC: Secreted protein with a SPRY domain; UGT: UDP-glucuronosyl transferase.
\end{abstract}

\section{Competing interests}

The authors declare that they have no competing interests.

\section{Authors' contributions}

$M B, J T J$ and PEU conceived and designed the research that was coordinated by $M B, C J L, N H, H B, A P, J T J$ and PEU. CJL and VB collected the biological material and prepared DNA and RNA. JAC, CJL, TK, AJR, PT, IJT, VB, PJAC, SEvdA, MH, LMJ, SM, HN, MZ and JEP-R analysed the data. MB, JAC, CJL, JTJ and PEU drafted the complete manuscript with contributions from the other authors. All authors read and approved the final manuscript.

\section{Authors' information}

Laura M Jones, Taisei Kikuchi, Adam J Reid, Peter Thorpe and Isheng J Tsa contributed equally as second authors.

\section{Acknowledgements}

We thank the many people at the Wellcome Trust Sanger Insitute who contributed to this work: Mark Simmonds, Natalie Smerdon, Dave Willey, Michael Quail, Matthew Jones and Richard Rance provided technical support in generating sequencing libraries; Robert Davies and Quan Lin arranged for data release to the SRA; Martin Aslett and Jacqueline Keane provided informatics support; Christine Lloyd assisted with sequencing management; Karen Brooks, Richard Clark, Olivia Lambert, Sarah Nichol and Alan Tracey assisted with curation and annotation of gene models. We thank Jennie Hibbard and Beverley Merry at the University of Leeds who provided technical support in generating biological material.

\section{Author details}

${ }^{1}$ Wellcome Trust Sanger Institute, Wellcome Trust Genome Campus, Cambridge CB10 1SA, UK. ${ }^{2}$ Centre for Plant Sciences, University of Leeds, Leeds LS2 9JT, UK. ${ }^{3}$ The James Hutton Institute, Invergowrie, Dundee DD2 5DA, UK. ${ }^{4}$ Forestry and Forest Products Research Institute, Tsukuba, Japan. ${ }^{5}$ Division of Parasitology, Department of Infectious Disease, Faculty of Medicine, University of Miyazaki, Miyazaki 889-1692, Japan. 'Biodiversity Research Center, Academia Sinica, Taipei 11529, Taiwan. ${ }^{7}$ Present address: School of Life Sciences, Centre for Biomolecular Sciences, University of Nottingham, Nottingham NG7 2RD, UK. ${ }^{8}$ Present address: Computational Bioscience Research Center (CBRC), Biological and Environmental Sciences and Engineering (BESE) Division, King Abdullah University of Science and
Technology, Thuwal 23955-6900, Kingdom of Saudi Arabia. ${ }^{9}$ Present address: Institute for Sustainable Agriculture (IAS), Spanish National Research Council (CSIC), Alameda del Obispo s/n Apdo 4084, 14080 Córdoba, Spain.

Received: 17 September 2013 Accepted: 3 March 2014

Published: 3 March 2014

\section{References}

1. Decraemer W, Hunt DJ: Structure and classification. In Plant Nematology. Edited by Perry RN, Moens M. Wallingford: CABI Publishing; 2006:3-32.

2. Nicol JM, Turner SJ, Coyne DL, den Nijs L, Hockland S, Maafi ZT: Current nematode threats to world agriculture. In Genomics and Molecular Genetics of Plant-nematode Interactions. Edited by Jones JT, Gheysen G, Fenoll C. Dordrecht, The Netherlands: Springer; 2011:21-43.

3. Perry RN, Moens M: Introduction to plant-parasitic nematodes: modes of parasitism. In Genomics and Molecular Genetics of Plant-nematode Interactions. Edited by Jones JT, Gheysen G, Fenoll C. Dordrecht, The Netherlands: Springer; 2011:3-20.

4. Baldwin JG, Nadler SA, Adams BJ: Evolution of plant parasitism among nematodes. Ann Rev Phytopathol 2004, 42:83-105.

5. Trudgill DL: Yield losses caused by potato cyst nematodes - a review of the current position in Britain and prospects for improvements. Ann Appl Biol 1986, 108:181-198

6. Evans K, Franco J, Descurrah MM: Distribution of species of potato cyst nematodes in South America. Nematologica 1975, 21:365-369.

7. Hockland S, Niere B, Grenier E, Blok V, Phillips M, Den Nijs L, Anthoine G, Pickup J, Viaene N: An evaluation of the implications of virulence in nonEuropean populations of Globodera pallida and G. rostochiensis for potato cultivation in Europe. Nematol 2012, 14:1-13.

8. Pylypenko LA, Uehara T, Phillips MS, Sigareva DD, Blok VC: Identification of Globodera rostochiensis and G. pallida in the Ukraine by PCR. Eur J Plant Pathol 2005, 111:39-46.

9. Skantar AM, Handoo ZA, Carta LK, Chitwood DJ: Morphological and molecular identification of Globodera pallida associated with potato in Idaho. J Nematol 2007, 39:133-144.

10. Minnis ST, Haydock PPJ, Ibrahim SK, Grove IG, Evans K, Russell MD: Potato cyst nematodes in England and Wales-occurrence and distribution. Ann Appl Biol 2002, 140:187-195.

11. Turner SJ: Population decline of potato cyst nematodes (Globodera rostochiensis, G. pallida) in field soils in Northern Ireland. Ann App/ Biol 1996, 129:315-322.

12. Trudgill DL, Phillips MS, Elliott MJ: Dynamics and management of the white potato cyst nematode Globodera pallida in commercial potato crops. Ann Appl Biol 2014, 164:18-34.

13. Clayton R, Storey M, Parker B, Ballingall M, Davies K: Impact of reduced pesticide availability on control of potato cyst nematodes and weeds in potato crops. Kenilworth: Potato Council Ltd.; 2008.

14. Lilley CJ, Atkinson HJ, Urwin PE: Molecular aspects of cyst nematodes. Mol Plant Pathol 2005, 6:577-588.

15. Sobczak M, Golinowski W: Cyst nematodes and syncytia. In Genomics and Molecular Genetics of Plant-nematode Interactions. Edited by Jones JT, Gheysen G, Fenoll C. Dordrecht, The Netherlands: Springer; 2011:61-82.

16. C. elegans sequencing consortium: Genome sequence of the nematode $C$. elegans: a platform for investigating biology. Science 1998, 282:2012-2018.

17. Ghedin E, Wang SL, Spiro D, Caler E, Zhao Q, Crabtree J, Allen JE, Delcher AL, Guiliano DB, Miranda-Saavedra D, Angiuoli SV, Creasy T, Amedeo P, Haas B, El-Sayed NM, Wortman JR, Feldblyum T, Tallon L, Schatz M, Shumway M, Koo H, Salzberg SL, Schobel S, Pertea M, Pop M, White O, Barton GJ, Carlow CKS, Crawford MJ, Daub J, et al: Draft genome of the filarial nematode parasite Brugia malayi. Science 2007, 317:1756-1760.

18. Blaxter M, Kumar S, Kaur G, Koutsovoulos G, Elsworth B: Genomics and transcriptomics across the diversity of the nematoda. Parasite Immunol 2012, 34:108-120.

19. Godel C, Kumar S, Koutsovoulos G, Ludin P, Nilsson D, Comandatore F, Wrobel N, Thompson M, Schmid CD, Goto S, Bringaud F, Wolstenholme A, Bandi C, Epe C, Kaminsky R, Blaxter M, Mäser P: The genome of the heartworm, Dirofilaria immitis, reveals drug and vaccine targets. FASEB J 2012, 26:4650-4661.

20. Desjardins CA, Cerqueira GC, Goldberg JM, Dunning Hotopp JC, Haas BJ, Zucker J, Ribeiro JM, Saif S, Levin JZ, Fan L, Zeng Q, Russ C, Wortman JR, 
Fink DL, Birren BW, Nutman TB: Genomics of Loa loa, a Wolbachia-free filarial parasite of humans. Nat Genet 2013, 45:495-500.

21. Bird DM, Williamson VM, Abad P, McCarter J, Danchin EGJ, CastagnoneSereno P, Opperman CH: The genomes of root-knot nematodes. Ann Rev Phytopathol 2009, 47:333-351.

22. Abad P, Gouzy J, Aury JM, Castagnone-Sereno P, Danchin EG, Deleury E, Perfus-Barbeoch L, Anthouard V, Artiguenave F, Blok VC, Caillaud M-C, Coutinho PM, Dasilva C, De Luca F, Deau F, Esquibet M, Flutre T, Goldstone JV, Hamamouch N, Hewezi T, Jaillon O, Jubin C, Leonetti P, Magliano M, Maier TR, Markov GV, McVeigh P, Pesole G, Poulain J, Robinson-Rechavi M, et al: Genome sequence of the metazoan plant-parasitic nematode Meloidogyne incognita. Nat Biotechnol 2008, 26:909-915.

23. Opperman CH, Bird DM, Williamson VM, Rokhsar DS, Burke M, Cohn J, Cromer J, Diener S, Gajan J, Graham S, Houfek TD, Liu Q, Mitros T, Schaff J, Schaffer R, Scholl E, Sosinski BR, Thomas VP, Windham E: Sequence and genetic map of Meloidogyne hapla: a compact nematode genome for plant parasitism. Proc Natl Acad Sci U S A 2008, 105:14802-14807.

24. Kikuchi T, Cotton JA, Dalzell J, Hasegawa K, Kanzaki N, McVeigh P, Takanashi T, Tsai IJ, Assefa SA, Cock PJ, Otto TD, Hunt M, Reid AJ, SanchezFlores A, Tsuchihara K, Yokoi T, Larsson MC, Miwa J, Maule AG, Sahashi N, Jones JT, Berriman M: Genomic insights into the origin of parasitism in the emerging plant pathogen Bursaphelenchus xylophilus. PLoS Pathog 2011, 7:e1002219.

25. Hoolahan AH, Blok VC, Gibson T, Dowton M: A comparison of three molecular markers for the identification of populations of Globodera pallida. J Nematol 2012, 44:7-17.

26. Stranneheim $\mathrm{H}$, Lundeberg J: Stepping stones in DNA sequencing. Biotechnol J 2012, 7:1063-1073.

27. Peters BA, Kermani BG, Sparks AB, Alferov $O$, Hong P, Alexeev A, Jiang $Y$, Dahl F, Tang YT, Haas J, Robasky K, Zaranek AW, Lee J-H, Ball MP, Peterson JE, Perazich H, Yeung G, Liu J, Chen L, Kennemer MI, Pothuraju K, Konvicka K, Tsoupko-Sitnikov M, Pant KP, Ebert JC, Nilsen GB, Baccash J, Halpern AL, Church GM, Drmanac R: Accurate whole-genome sequencing and haplotyping from 10 to 20 human cells. Nature 2012, 487:190-195

28. Mitreva M, Jasmer DP, Zarlenga DS, Wang Z, Abubucker S, Martin J, Taylor CM, Yin Y, Fulton L, Minx P, Yang S-P, Warren WC, Fulton RS, Bhonagiri V, Zhang X, Hallsworth-Pepin K, Clifton SW, McCarter JP, Appleton J, Mardis ER, Wilson RK: The draft genome of the parasitic nematode Trichinella spiralis. Nat Genet 2011, 43:228-235.

29. Grisi E, Burrows PR, Perry RN, Hominick W: The genome size and chromosome complement of the potato cyst nematode Globodera pallida. Fund Appl Nematol 1995, 18:67-70.

30. van der Voort JNAMR, van Enckevort ELJG, Pijnacker LP, Helder J, Gommers FJ, Bakker J: Chromosome number of the potato cyst nematode Globodera rostochiensis. Fund Appl Nematol 1996, 19:369-374.

31. Merlin J, Goldstein A, Goldstein P: Three-dimensional ultrastructura karyotype analysis from the meiotic parthenogenetic nematode Heterodera betulae. J Nematol 2003, 35:228-231.

32. Goldstein P, Triantaphyllou AC: Karyotype analysis of the plant-parasitic nematode Heterodera glycines by electron microscopy 1. Diploid. J Cell Sci 1979, 40:171-179.

33. Goldstein P, Triantaphyllou AC: Karyotype analysis of Meloidogyne hapla by 3-D reconstruction of synaptonemal complexes from electron microscopy of serial sections. Chromosoma 1978, 70:131-139.

34. Coghlan A: Nematode genome evolution. In WormBook. Edited by The C. elegans Research Community. http://www.wormbook.org

35. Thomas VP, Fudali SL, Schaff JE, Liu QL, Scholl EH, Opperman CH, Bird DM, Williamson VM: sequence-anchored linkage map of the plant-parasitic nematode Meloidogyne hapla reveals exceptionally high genome-wide recombination. G3-Genes Genomes. G3-Genes Genomes Genetics 2012, 2:815-824.

36. Keeling PJ: Reduction and compaction in the genome of the apicomplexan parasite Cryptosporidium parvum. Dev Cell 2004, 6:614-616.

37. Animal genome size database. http://www.genomesize.com.

38. Leroy S, Bouamer S, Morand S, Fargette M: Genome size of plant-parasitic nematodes. Nematol 2007, 9:449-450.

39. Costa JC, Lilley CJ, Urwin PE: Caenorhabditis elegans as a model for plantparasitic nematodes. Nematol 2007, 9:3-16

40. Jones LM, De Giorgi C, Urwin PE: C. elegans as a resource for studies on plant parasitic nematodes. In Genomics and Molecular Genetics of Plant- nematode Interactions. Edited by Jones JT, Gheysen G, Fenoll C. Dordrecht, The Netherlands: Springer; 2011:175-220.

41. Allen MA, Hillier LW, Waterston RH, Blumenthal T: A global analysis of $C$. elegans trans-splicing. Genome Res 2011, 21:255-264.

42. van Bers NEM: Characterization of genes coding for small hypervariable peptides in Globodera rostochiensis, PhD thesis. Wageningen: Wageningen University; 2008

43. Kass J, Jacob TC, Kim P, Kaplan JM: The EGL-3 proprotein convertase regulates mechanosensory responses of Caenorhabditis elegans. J Neurosci 2001, 21:9265-9272.

44. Shakir MA, Fukushige T, Yasuda H, Miwa J, Siddiqui SS: C. elegans osm-3 gene mediating osmotic avoidance behaviour encodes a kinesin-like protein. Neuroreport 1993, 4:891-894.

45. Salkoff L, Wei AD, Baban B, Butler A, Fawcett G, Ferreira G, Santi CM: Potassium channels in C. elegans. In WormBook. Edited by The C. elegans Research Community. http://www.wormbook.org.

46. Behm CA: The role of trehalose in the physiology of nematodes. Int $J$ Parasitol 1997, 27:215-229.

47. Jones JT, Kumar A, Pylypenko LA, Thirugnanasambandam A, Castelli L, Chapman S, Cock PJA, Grenier E, Lilley CJ, Phillips MS, Blok VC: Identification and functional characterization of effectors in expressed sequence tags from various life cycle stages of the potato cyst nematode Globodera pallida. Mol Plant Pathol 2009, 10:815-828.

48. Qin L, Overmars B, Helder J, Popeijus H, van der Voort JR, Groenink W, van Koert P, Schots A, Bakker J, Smant G: An efficient CDNA-AFLP-based strategy for the identification of putative pathogenicity factors from the potato cyst nematode Globodera rostochiensis. Mol Plant-Microbe Int 2000, 13:830-836.

49. Gao BL, Allen R, Maier T, Davis EL, Baum TJ, Hussey RS: The parasitome of the phytonematode Heterodera glycines. Mol Plant-Microbe Int 2003, 16:720-726

50. van Megen $\mathrm{H}$, van den Elsen $\mathrm{S}$, Holterman $\mathrm{M}$, Karssen $\mathrm{G}$, Mooyman $\mathrm{P}$, Bongers T, Holovachov O, Bakker J, Helder J: A phylogenetic tree of nematodes based on about 1200 full-length small subunit ribosomal DNA sequences. Nematology 2009, 11:927-950.

51. Haegeman A, Jones JT, Danchin EGJ: Horizontal gene transfer in nematodes: A catalyst for plant parasitism? Mol Plant-Microbe Int 2011 24:879-887.

52. Vanholme B, Haegeman A, Jacob J, Cannoot B, Gheysen G: Arabinogalactan endo-1,4- $\beta$-galactosidase: a putative cell wall-degrading enzyme of plant-parasitic nematodes. Nematology 2009, 11:739-747.

53. Jones JT, Furlanetto C, Bakker E, Banks B, Blok V, Chen Q, Phillips M, Prior A: Characterization of a chorismate mutase from the potato cyst nematode Globodera pallida. Mol Plant Pathol 2003, 4:43-50.

54. Craig JP, Bekal S, Niblack T, Domier L, Lambert KN: Evidence for horizontally transferred genes involved in the biosynthesis of vitamin B-1, B-5, and B-7 in Heterodera glycines. J Nematol 2009, 41:281-290.

55. Hussey RS, Mimms CW: Ultrastructure of esophogeal glands and their secretory granules in the root-knot nematode Meloidogyne incognita. Protoplasma 1990, 162:99-107.

56. Smant G, Goverse A, Stokkermans JPWG, De Boer JM, Pomp H, Zilverentant JF, Overmars HA, Helder J, Schots A, Bakker J: Potato root diffusateinduced secretion of soluble, basic proteins originating from the subventral esophageal glands of potato cyst nematodes. Phytopathology 1997, 87:839-845.

57. Lu SW, Chen S, Wang J, Yu H, Chronis D, Mitchum MG, Wang X: Structural and functional diversity of CLAVATA3/ESR (CLE)-like genes from the potato cyst nematode Globodera rostochiensis. Mol Plant Microbe Int 2009, 22:1128-1142

58. Rehman S, Postma W, Tytgat T, Prins P, Qin L, Overmars H, Vossen J, Spiridon LN, Petrescu AJ, Goverse A, Bakker J, Smant G: A secreted SPRY domain-containing protein (SPRYSEC) from the plant-parasitic nematode Globodera rostochiensis interacts with a CC-NB-LRR protein from a susceptible tomato. Mol Plant-Microbe Int 2009, 22:330-340.

59. Sacco MA, Koropacka K, Grenier E, Jaubert MJ, Blanchard A, Goverse A, Smant G, Moffett P: The cyst nematode SPRYSEC protein RBP-1 elicits Gpa2- and RanGAP2-dependent plant cell death. PLoS Pathog 2009, 5:e1000564.

60. O'Brien JA, Daudi A, Butt VS, Bolwell GP: Reactive oxygen species and their role in plant defence and cell wall metabolism. Planta 2012, 236:765-779. 
61. Cabreiro F, Ackerman D, Doonan R, Araiz C, Back P, Papp D, Braeckman BP, Gems D: Increased life span from overexpression of superoxide dismutase in Caenorhabditis elegans is not caused by decreased oxidative damage. Free Radical Bio Med 2011, 51:1575-1582.

62. Robertson L, Robertson WM, Sobczak M, Bakker J, Tetaud E, Arinagayayam MR, Ferguson MAJ, Fairlamb AH, Jones JT: Cloning, expression and functional characterisation of a thioredoxin peroxidase from the potato cyst nematode Globodera rostochiensis. Mol Biochem Parasitol 2000, 111:41-49.

63. Jones JT, Reavy B, Smant G, Prior AE: Glutathione peroxidases of the potato cyst nematode Globodera rostochiensis. Gene 2004, 324:47-54.

64. Noctor G, Mhamdi A, Chaouch S, Han Y, Neukermans J, Marquez-Garcia B, Queval G, Foyer $\mathrm{CH}$ : Glutathione in plants: an integrated overview. Plant Cell Environ 2012, 35:454-484.

65. Baldacci-Cresp F, Chang C, Maucourt M, Deborde C, Hopkins J, Lecomte P, Bernillon S, Brouquisse R, Moing A, Abad P, Hérouart D, Puppo A, Favery B, Frendo P: (Homo)glutathione deficiency impairs root-knot nematode development in Medicago truncatula. PLoS Pathog 2012, 8:e1002471.

66. Lu SC: Glutathione synthesis. Biochim Biophys Acta 2013, 1830:3143-3153.

67. Jirschitzka J, Schmidt GW, Reichelt M, Schneider B, Gershenzon J, D'Auria JC: Plant tropane alkaloid biosynthesis evolved independently in the Solanaceae and Erythroxylaceae. Proc Natl Acad Sci U S A 2012, 109:10304-10309.

68. Lindblom TH, Dodd AK: Xenobiotic detoxification in the nematode Caenorhabditis elegans. J Exp Zool A Comp Exp Biol 2006, 305:720-730.

69. Laing ST, Ivens A, Butler V, Ravikumar SP, Laing R, Woods DJ, Gilleard JS: The transcriptional response of Caenorhabditis elegans to ivermectin exposure identifies novel genes involved in the response to reduced food intake. PLOS ONE 2012, 7:e31367.

70. van Rossum AJ, Brophy PM, Tait A, Barrett J, Jefferies JR: Proteomic identification of glutathione S-transferases from the model nematode Caenorhabditis elegans. Proteomics 2001, 1:1463-1468.

71. Robinson-Rechavi M, Maina CV, Gissendanner CR, Laudet V, Sluder A: Explosive lineage-specific expansion of the orphan nuclear receptor HNF4 in nematodes. J Mol Evol 2005, 60:577-586.

72. Taubert S, Ward JD, Yamamoto KR: Nuclear hormone receptors in nematodes: evolution and function. Mol Cell Endocrinol 2011, 334:49-55.

73. Zarkower D: Somatic sex determination. In WormBook. Edited by The C. elegans Research Community. http://www.wormbook.org.

74. Mugniery D, Fayet G: Sex determination in Globodera pallida. Rev Nematol 1981, 4:41-45

75. Trudgill DL: The effect of environment on sex determination in Heterodera glycines. Nematologica 1967, 13:263-272.

76. Triantaphyllou AC: Environmental sex differentation of nematodes in relation to pest management. Ann Rev Phytopathol 1973, 11:441-462.

77. Phillips M, Forrest J, Farrer A: Invasion and development of juveniles of Globodera pallida in hybrids of Solanum vernei x S. tuberosum. Ann Appl Biol 1982, 100:337-344

78. Spears JF: The golden nematode handbook: survey, laboratory, control and quarantine procedures. Washington, DC: U.S. Department of Agriculture, Agricultural Research Service; 1968.

79. Elling AA, Mitreva M, Recknor J, Gai X, Martin J, Maier TR, McDermott JP, Hewezi T, Bird DM, Davis EL, Hussey RS, Nettleton D, McCarter JP, Baum TJ: Divergent evolution of arrested development in the dauer stage of Caenorhabditis elegans and the infective stage of Heterodera glycines. Genome Biol 2007, 8:R211.

80. Endo PJ: Ultrastructure of the intestine of the second and third juvenile stages of Heterodera glycines. P Helm Soc Wash 1988, 55:117-131.

81. Hu PJ: Dauer. In WormBook. Edited by The C. elegans Research Community. http://www.wormbook.org.

82. Sommer RJ: Homology and the hierarchy of biological systems. BioEssays 2008, 30:653-658.

83. Fire A, Xu SQ, Montgomery MK, Kostas SA, Driver SE, Mello CC: Potent and specific genetic interference by double-stranded RNA in Caenorhabditis elegans. Nature 1998, 391:806-811.

84. Urwin PE, Lilley CJ, Atkinson HJ: Ingestion of double-stranded RNA by preparasitic juvenile cyst nematodes leads to RNA interference. $\mathrm{Mol}$ Plant-Microbe Interact 2002, 15:747-752.

85. Lilley CJ, Davies $\sqcup$, Umwin PE: RNA interference in plant parasitic nematodes: a summary of the current status. Parasitology 2012, 139:630-640.
86. Dalzell JJ, McVeigh P, Warnock ND, Mitreva M, Bird DM, Abad P, Fleming CC, Day TA, Mousley A, Marks NJ, Maule AG: RNAi effector diversity in nematodes. PLoS Negl Trop Dis 2011, 5:e1176.

87. Tijsterman M, May RC, Simmer F, Okihara KL, Plasterk RHA: Genes required for systemic RNA interference in Caenorhabditis elegans. Curr Biol 2004, 14:111-116.

88. Dalzell JJ, McMaster S, Fleming CC, Maule AG: Short interfering RNAmediated gene silencing in Globodera pallida and Meloidogyne incognita infective stage juveniles. Int J Parasitol 2010, 40:91-100.

89. Kimber MJ, McKinney S, McMaster S, Day TA, Fleming CC, Maule AG: flp gene disruption in a parasitic nematode reveals motor dysfunction and unusual neuronal sensitivity to RNA interference. FASEB J 2007, 21:1233-1243.

90. Kimber MJ, Fleming CC: Neuromuscular function in plant parasitic nematodes: a target for novel control strategies? Parasitology 2005, 131:129-142.

91. Brown LA, Jones AK, Buckingham SD, Mee CJ, Sattelle DB: Contributions from Caenorhabditis elegans functional genetics to antiparasitic drug target identification and validation: nicotinic acetylcholine receptors, a case study. Int J Parasitol 2006, 36:617-624.

92. Pais M, Win J, Yoshida K, Etherington GJ, Cano LM, Raffaele S, Banfield MJ, Jones A, Kamoun S, Saunders DGO: From pathogen genomes to host plant processes: the power of plant parasitic oomycetes. Genome Biol 2013, 14:211.

93. Soanes DM, Richards TA, Talbot NJ: Insights from sequencing fungal and oomycete genomes: What can we learn about plant disease and the evolution of pathogenicity? Plant Cell 2007, 19:3318-3326.

94. Spanu PD: The genomics of obligate (and nonobligate) biotrophs. Ann Rev Phytopathol 2012, 50:91-109.

95. Phillips MS, Trudgill DL: Variation of virulence, in terms of quantitative reproduction of Globodera pallida populations, from Europe and South America, in relation to resistance from Solanum vernei and $S$. tuberosum ssp andigena CPC 2802. Nematologica 1998, 44:409-423.

96. Stanke M, Schoffmann O, Morgenstern B, Waack S: Gene prediction in eukaryotes with a generalized hidden Markov model that uses hints from external sources. BMC Bioinformatics 2006, 7:62

97. Hunter S, Jones P, Mitchell A, Apweiler R, Attwood TK, Bateman A, Bernard T, Binns D, Bork P, Burge S, de Castro E, Coggill P, Corbett M, Das U, Daugherty L, Duquenne L, Finn RD, Fraser M, Gough J, Haft D, Hulo N, Kahn D, Kelly E, Letunic I, Lonsdale D, Lopez R, Madera M, Maslen J, McAnulla C, McDowall J: InterPro in 2011: new developments in the family and domain prediction database. Nucl Acids Res 2012, 40:D306-D312.

98. Conesa A, Gotz S, Garcia-Gomez JM, Terol J, Talon M, Robles M: Blast2GO: a universal tool for annotation, visualization and analysis in functional genomics research. Bioinformatics 2005, 21:3674-3676.

99. Li L, Stoeckert CJ, Roos DS: OrthoMCL: identification of ortholog groups for eukaryotic genomes. Genome Res 2003, 13:2178-2189.

100. Roth AC, Gonnet GH, Dessimoz C: Algorithm of OMA for large-scale orthology inference. BMC Bioinformatics 2008, 9:518.

101. Elsworth B, Wasmuth J, Blaxter M: NEMBASE4: the nematode transcriptome resource. Int J Parasitol 2011, 41:881-894.

doi:10.1186/gb-2014-15-3-r43

Cite this article as: Cotton et al:: The genome and life-stage specific transcriptomes of Globodera pallida elucidate key aspects of plant parasitism by a cyst nematode. Genome Biology 2014 15:R43.

\section{Submit your next manuscript to BioMed Central and take full advantage of:}

- Convenient online submission

- Thorough peer review

- No space constraints or color figure charges

- Immediate publication on acceptance

- Inclusion in PubMed, CAS, Scopus and Google Scholar

- Research which is freely available for redistribution 